\title{
Tropospheric and Stratospheric Conductivity Measurements in Brazil
}

\author{
M.M.F. Saba \\ O. Pinto Jr. \\ I.R.C.A. Pinto \\ O. Mendes Jr.
}

Instituto Nacional de Pesquisas Espaciais -INPE

Conductivity measurements were carried out during a balloon flight launched from Cachoeira Paulista, Brazil $\left(22^{\circ} 44^{\prime} \mathrm{S}, 44^{\circ} 56^{\prime} \mathrm{W}\right)$ on Jan 26, 1994. For the first time negative and positive conductivity profiles with altitude were obtained in Brazil. Along its trajectory the balloon passed over three thunderstorms, as identified by video on-board images. The data give an unique opportunity to study the stratospheric conductivity variations.

\section{INTRODUCTION}

Conductivity measurements in the troposphere and stratosphere have been reported by several authors (e.g. Bering et al., 1980; Holzworth and Chiu, 1982; Holzworth et al., 1986; Byrne et al., 1988; Pinto et al., 1988; Hu et al., 1989). The measurements show that in the troposphere the conductivity increases almost exponentially with the altitude and in the stratosphere it is influenced locally by thunderstorms.

On January 26, 1994, a stratospheric balloon was launched from Cachoeira Paulista, Brazil $\left(22^{\circ} 44^{\prime}\right.$ $\mathrm{S}, 44^{\circ} 56^{\prime} \mathrm{W}$ ) carrying a double probe electric field detector to measure the conductivity in the troposphere and stratosphere. The payload also carried a video camcorder model Panasonic PV-704, looking downward. Negative and positive conductivity were measured each 10 minutes during about 3 hours in daytime. In the stratosphere, the positive conductivity was found to be contaminated by photoelectric emission, and the data were not considered in this paper.

In this paper the first conductivity profiles for negative and positive conductivities obtained in Brazil are presented. The negative conductivity measurements obtained in the stratosphere are also presented and discussed in terms of thunderstorm related variations. As far we know, this is the first conductivity data in the stratosphere supported by video images.

\section{RESULTS}

Figure 1 shows the negative and positive profiles obtained on Jan 26, 1994. Because the high impedance of the atmosphere, the double probe technique is useful only for altitudes above $10 \mathrm{~km}$ (Byme et al., 1988). In order to avoid such a problem, only data above $16 \mathrm{~km}$ were considered. Differently of the negative conductivity, the positive conductivity in $26 \mathrm{~km}$ already shows the influence of photoelectric emissions, which causes an increase in the measured value. A same behavior was found by Chakrabarty et al. (1994). So, the positive conductivity value in this altitude was not considered in the calculation of the best fit, represented in the figure by a straight line. The linear fits give conductivity scale heights of $5.2 \mathrm{~km}$ for negative and $5.8 \mathrm{~km}$ for positive conductivity. Figure 2 shows the negative conductivity measurements in the stratosphere obtained on Jan 26, 1994. Due to the small variations of the balloon altitude along the flight, the data are normalized to $25.8 \mathrm{~km}$ of altitude using the scale height of $5.2 \mathrm{~km}$. The periods when the balloon was just over the thunderstorms are indicated by ash bars. During these periods, the electric field recovery curves not follow an exponentially curve, and in consequence, no data were available. Also during these periods the electric field remains saturated above the $4 \mathrm{~V} / \mathrm{m}$ threshold. This behavior may be associated with the high radiation albedo in the top of the thunderstorms (Kreith, 1975; Rao et al., !990).

\section{DISCUSSION}

The negative and positive conductivity values obtained during the ascension of the balloon launched on Jan 26, 1994, in Brazil, showed almost the same value. No evidence was found that the positive conductivity tends to be 10 to $15 \%$ higher than the negative conductivity, as it has been claimed by Gringel et al. (1986) and $\mathrm{Hu}$ et al. (1994). In consequence, almost the same scale heights were obtained. The values of scale height, $5.2 \mathrm{~km}$ for negative and $5.8 \mathrm{~km}$ for positive conductivity, are in general agreement with other measurements made in different parts of the world (see, for example, Holzworth, 1991).

The average value of the conductivity in the stratosphere, shown in figure 2 , is in reasonable agreement with the average value obtained by Pinto et al. (1988) in the same region during nighttime. The variation of the conductivity in figure 2 shows a systematic decrease when the balloon approaches to a thunderstorm. The conductivity drops by a factor of about 2 in the vicinity of the first thunderstorm, and by a factor of about 1.5 in the vicinity of the second thunderstorm. The same tendency seems to occur in the vicinity of the third thunderstorm. The on-board video images show that in all cases the balloon passed just 
over the storm. The same behavior in the conductivity was seen by Pinto et al. (1988), although no images were available at that time. We suggest that the systematic decrease of the stratospheric conductivity may be explained by injection in the stratosphere of air parcels containing low concentration of small ions from the top of the thunderstorms, reducing the total concentration of small ions. Such parcels can be found in the interior of the thunderstorms (Makino and Ogawa, 1985).

\section{CONCLUSIONS}

The main conclusions of this paper are: - the first negative and positive conductivity profiles in the troposphere and stratosphere in Brazil were obtained. The scale heights are in reasonable agreement with measurements in other parts of the world. - the negative conductivity in the stratosphere shows a decrease just over a thunderstorm.

\section{ACKNOWLEDGMENTS.}

The authors would like to thank the Fundação de Amparo à Pesquisa do Estado de São Paulo for providing support through the project 93/0907-0.

\section{REFERENCES}

Bering, E.A.; Rosenberg, T.J.; Benbrook, J.R.; Detrick, D.; Matthews, D.L.; Rycroft, M.J.; Saunders, M.A. and Sheldon, W.R. Electric fields, electron precipitation, and VLF radiation during a simultaneous magnetospheric substorm and atmospheric thunderstorm. J. Geophys. Res., 85(A1):55-72, 1980. Byrne, G.J.; Benbrook, J.R.; Bering, E.A.; Oró, D.; Seubert, C.O. and Sheldon, W.R. Observations of the stratospheric conductivity and its variation at three latitudes. J. Geophys. Res., 93: 3879-3891, 1988.
Chakrabarty, D.K.; Lal, M.; Beig, G.; Sidhu, J.S. and Das, S.R. Balloon measurements of stratospheric ion conductivities over the tropics. J. Atmos. Terr. Phys., 56(9):1107-1115, 1994.

Gringel, W.; Rosen, J.M.; Hofmann. D.J. Electrical structure from 0 to 30 kilometers. In: The earth's electrical environment. Washington, DC, National Academy, 1986. p. 183-194. (Studies in geophysics).

Holzworth, R.H. Conductivity and electrical field variations with altitude in the stratosphere. Journal of Geophysical Research, 96(D7):12857-12864, 1991.

Holzworth, R.H.; Chiu, Y. T. Sferics in the stratosphere. In: Volland, H., ed. Handbook of Atmospherics. Florida, CRC, 1982, v.2.

Holzworth, R.H.; Norville, K.W.; Kintner, P.M.; Powel, S.P. Stratospheric conductivity variations over thunderstorms. J. Geophys. Res., 91(D12):13257$13263,1986$.

Hu, H.; Holzworth, R.H.; Li, Y.Q. Thunderstorm related variations in stratospheric conductivity measurements. J. Geophys. Res., 94(D13):1642916435, 1989.

Kreith, F. Energy balance and a flight model. In: , ed. Scientific Ballooning Handbook., 1975.

(NCAR-TN/IA-99)

Makino, M.; Ogawa, T. Quantitative estimation of global circuit. J. Geophys. Res., 90(D4):5961-5966, 1985.

Pinto, I.R.C.A.; Pinto Jr., O.; Gonzalez, W.D.; Dutra, S.L.G.; Wygant, J.; Mozer, F.S. Stratospheric electric field and conductivity measurements over electrified convective clouds in the South American region, J. Geophys. Res., 93(D1):709-715, 1988.

Rao, P.K.; Holmes, S.J.; Anderson, R.K. Winston, J.S.; Lehr, P.E. (eds.) Weather Satellite: Systems, Data, Environmental Applications. American Meteorological Society, Boston, EUA. 1990. 503p.

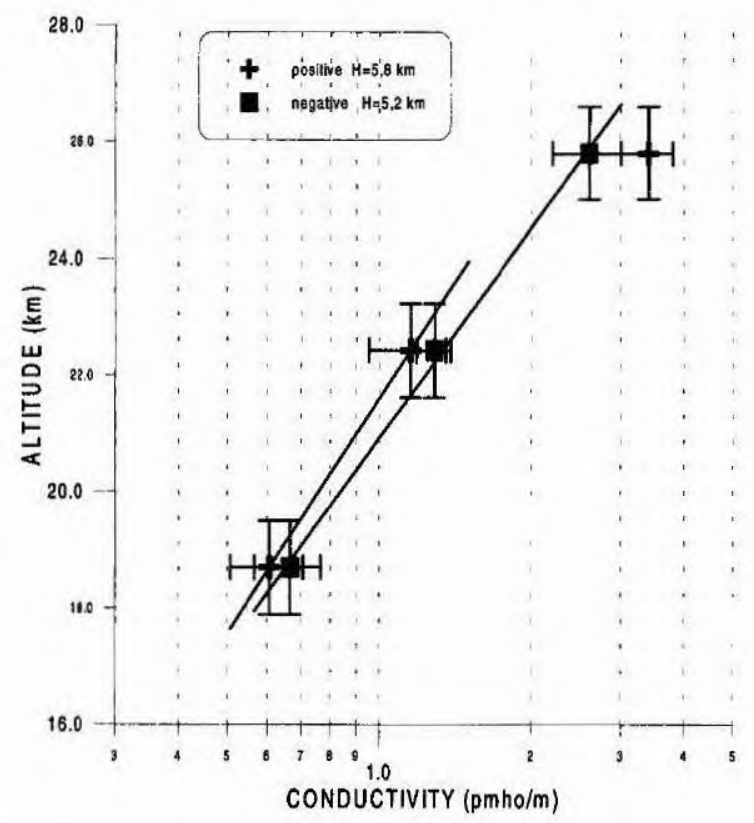

Figure 1 - Vertical profile of negative and positive conductivity obtained on Jan. 26, 1994. 


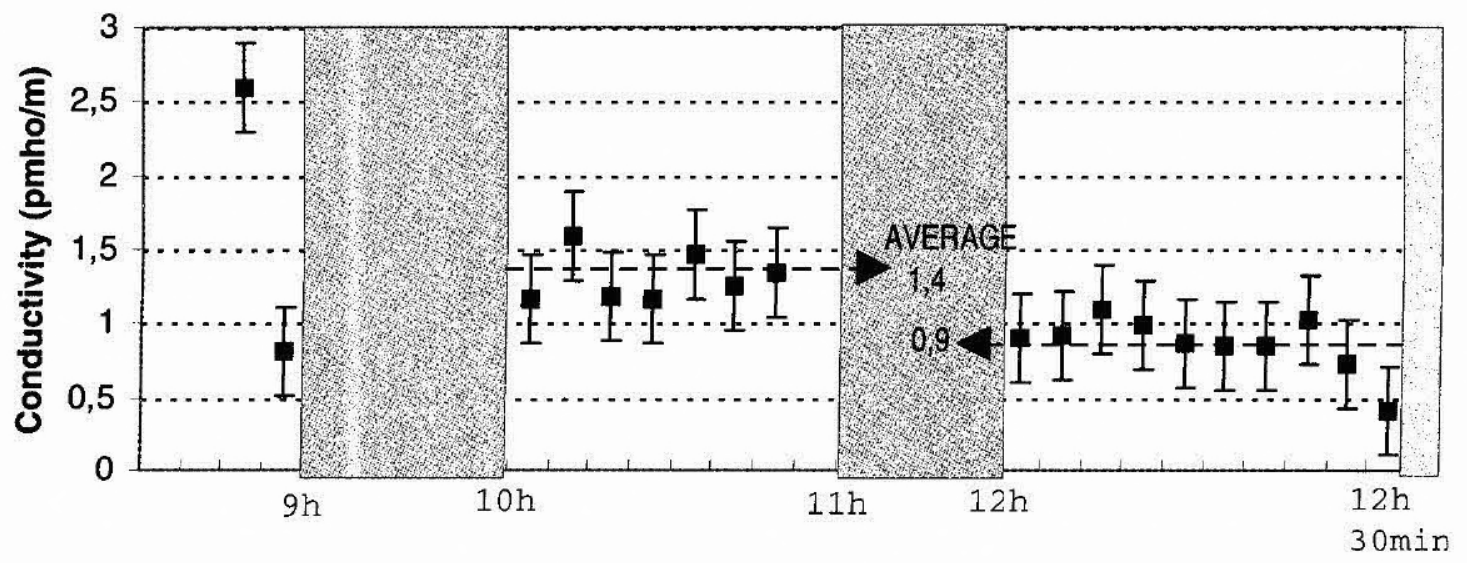

Figure 2 - Negative conductivity measurements obtained on Jan. 26, 1994. 